\title{
A Novel DTC Method with Efficiency Improvement of IM for EV Applications
}

\author{
Hilmi Aygun \\ Electrical-Electronics Engineering Department \\ Karabuk University \\ Karabuk, Turkey \\ hilmiaygun@karabuk.edu.tr
}

\author{
Mustafa Aktas \\ Department of Electrical and Electronics Engineering \\ Ondokuz Mayıs University \\ Samsun, Turkey \\ mustafa.aktas@omu.edu.tr
}

\begin{abstract}
Induction motor (IM) stator flux optimization is very important in order to get increasing running distance per battery charge of electric vehicles (EVs). This study introduces a new direct torque control (DTC) method for efficiency improvement of IM in EV applications. Also, it is proposed to decrease the torque ripple of DTC based IM. Generally, loss minimization algorithms can be simplified by neglecting the core loss or the effect of leakage inductance in the motor model. However, neglecting the core loss causes an error in torque control of DTC. Beside this, exact loss minimization cannot be achieved since a large voltage drop across leakage inductance occurs especially in high-speed region. In the proposed method, the motor model is simplified by neglecting the current in the core loss resistance branch instead of neglecting the core loss and the effect of leakage inductance. The proposed method is simulated in Matlab for variable speeds and loads. Results show that it provides a significant reduction of losses and decreases the torque ripple of IM drives.
\end{abstract}

Keywords-efficiency improvement; electric vehicle; induction motor; model-based controller; direct torque control

\section{INTRODUCTION}

The popularity of EVs has been growing up due to their quiet operation and harmless emissions. EVs can be improved by regenerative braking systems which convert kinetic energy back into stored electricity. Generally, EV applications are of great industrial interest $[1,2]$, however, the charging time of the batteries is very long. Therefore, electrical energy must be used optimally for increasing running distance for every battery charge. As a result, the losses of electric motors must be reduced for efficiency optimization [3-5]. Squirrel cage induction motor (IM) is widely accepted as the best candidate for EVs thanks to its reliability, ruggedness, low maintenance and cost. IMs are particularly well suited for traction drive environments [6]. They have good efficiency at rated load when operating at steady state. However, their efficiency is low at light loads due to increased core losses [7]. DTC method appears as a suitable way to improve dynamic performance of IMs as it provides a fast torque response and robustness to motor parameter variations. However, DTC has some serious problems such as variable switching frequency and a high amount of torque ripple caused by hysteresis controller [8-9]. If the hysteresis band range is selected narrow, the thermal limits of the power switches are enforced due to the switching frequency. Otherwise, if the hysteresis band range is selected in wide range, the torque ripple increases due to decreased switching frequency [10]. The torque ripple can be decreased by stator flux optimizing that improves the efficiency of IM.

Generally, two kinds of methods are used for increasing IM efficiency. One of them is a search controller is based on measurements of parameters like the input power of the motor. The other method, called loss model-based controller, needs the mathematical model of the motor. The aim of these methods is to find optimum flux which will provide maximum efficiency, especially at light loads $[11,12]$. In loss model-based controller, the term of total losses, consisting of copper and core losses, is determined as a function of flux, torque and speed. In this method, the model must include the core loss resistance which is usually ignored. Generally, optimal flux value can be obtained at different load torque and speed conditions by setting the derivative of total loss with respect to the flux to zero. Therefore, the convergence speed of loss model-based controller is fast, and as a result, this method is suitable for EV applications [13]. In search control algorithm, the flux is decreased step by step, and at the same time the input power of motor is measured until the maximum efficiency point is obtained. The biggest advantage of this method is that it does not require prior knowledge of motor parameters which might change by temperature. Since this method does not need a mathematical model, it is not affected by saturation. In this method, the step range of flux must be as small as possible to obtain a low flux ripple. However, if the step range of flux is chosen very small, convergence problem can occur [14].

Many different optimal control methods to improve energy efficiency of IM have been proposed, e.g. loss minimization algorithms, including search controller presented in [15-17]. Convergence time of a search controller is longer than a loss model-based controller. Since the speed and load torque of EVs change frequently, search control algorithm is not sufficient for EV applications because of its low convergence speed. A loss model-based control method was proposed in [18] for reducing the losses of IM. According to this method, when two axis power loss components are equal in the stator-fixed $d-q$ frame, maximum efficiency is obtained for a given load and speed. In 
this loss minimization method, a PI controller is used to produce the reference stator flux. However, power loss components have harmonic pollution caused by current distortion. Therefore, tuning the mentioned PI controller is very difficult. Another type of loss model-based method of IM for high operating life of the battery in the EVs was presented in [3]. In this method, the losses are quantified in the synchronous rotating $d-q$ frame. The effect of leakage inductances is neglected to find optimal rotor flux value. However, the maximum efficiency point cannot be determined as a high voltage drop across the leakage inductances is ignored, especially in high speed region. For the efficiency optimization of vector control-based IMs, maximum efficiency operating point is obtained without neglecting leakage inductances thanks to the reference frame fixed to the rotor magnetizing current in $[19,20]$. These studies require an additional controller to obtain optimal reference flux component. However, the additional controller increases the method complexity. In [21-22], a loss model-based approach neglecting core loss is presented for IM drives. However, neglecting the core losses for simplifying the model causes an error in the torque control of DTC. As EV motors have low inductance, the current ripple causes a significant amount of core losses, especially in high speed region.

In this paper, DTC method combined with an online loss model-based controller is proposed to minimize the losses of EV induction motors at variable load and speed conditions. Also, it is proposed to decrease the torque ripple which is a problem of classical DTC method based on variable switching frequency. In this method, a simplification for modeling of losses is made by neglecting the current in the core loss resistance branch of the equivalent circuit of IM in the synchronous reference frame. Also, the proposed method does not neglect the core losses and effect of the leakage inductances. Optimal stator flux value of IM is obtained by setting the derivative of total loss with respect to the stator flux to zero.

\section{DIRECT TORQUE CONTROL}

Direct torque control (DTC) method consists of estimators and hysteresis comparators for electromagnetic torque and stator flux, and an optimal switching table. In a three-phase induction motor, torque and stator flux are given by [23]:

$$
\begin{aligned}
& T_{e}=\frac{3}{2} P \overline{\psi_{s}} \times \bar{I}_{s} \\
& \bar{\psi}_{s}=\int\left(\bar{V}_{s}-R_{s} \overline{I_{s}}\right) d t
\end{aligned}
$$

where $P$ is the pole pair, $\bar{\psi}_{\underline{S}}$ is the stator flux linkage vector, $\bar{I}_{S}$ is the stator current vector, $\bar{V}_{S}$ is the stator voltage vector, and $R_{s}$ is the stator resistance. Torque and flux references are compared with the estimated values to determine the error signals. Flux and torque hysteresis comparators produce control signals. According to the control signals and stator flux position, the appropriate stator voltage from optimum switching table (Table I) is applied to the inverter circuit. Therefore, the required torque can be obtained effectively thanks to the rotating stator flux vector as fast as required [24].
Figure 1 is given as an example for the stator flux control. The stator voltage vectors are moved in a rotating counterclockwise direction with staying between the hysteresis bands. Stator flux amplitude can be increased or decreased by selecting different stator voltage vectors. The block scheme of DTC based on IM drives is given in Figure 2. PI controller produces the torque reference value according to the error between reference and measured speeds. This way torque and speed can be controlled.

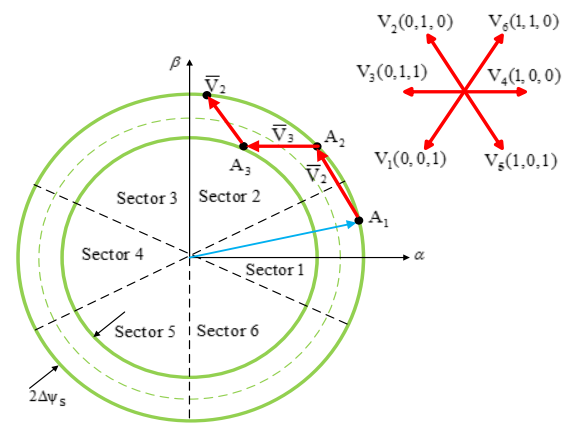

Fig. 1. Stator flux trajectory by suitable voltage vector selection.

TABLE I. OPTIMUM SWITCHING TABLE FOR DTC BASED IM

\begin{tabular}{|c|c|c|c|c|c|c|c|}
\hline $\mathbf{d} \boldsymbol{\psi}$ & $\boldsymbol{d} \boldsymbol{T}_{\boldsymbol{e}}$ & Sect. 1 & Sect. 2 & Sect. 3 & Sect. 4 & Sect. 5 & Sect. 6 \\
\hline \multirow{3}{*}{1} & 1 & $\mathrm{~V}_{6}$ & $\mathrm{~V}_{2}$ & $\mathrm{~V}_{3}$ & $\mathrm{~V}_{1}$ & $\mathrm{~V}_{5}$ & $\mathrm{~V}_{4}$ \\
\cline { 2 - 8 } & 0 & $\mathrm{~V}_{7}$ & $\mathrm{~V}_{0}$ & $\mathrm{~V}_{7}$ & $\mathrm{~V}_{0}$ & $\mathrm{~V}_{7}$ & $\mathrm{~V}_{0}$ \\
\cline { 2 - 8 } & -1 & $\mathrm{~V}_{5}$ & $\mathrm{~V}_{4}$ & $\mathrm{~V}_{6}$ & $\mathrm{~V}_{2}$ & $\mathrm{~V}_{3}$ & $\mathrm{~V}_{1}$ \\
\hline \multirow{3}{*}{0} & 1 & $\mathrm{~V}_{2}$ & $\mathrm{~V}_{3}$ & $\mathrm{~V}_{1}$ & $\mathrm{~V}_{5}$ & $\mathrm{~V}_{4}$ & $\mathrm{~V}_{6}$ \\
\cline { 2 - 8 } & 0 & $\mathrm{~V}_{0}$ & $\mathrm{~V}_{7}$ & $\mathrm{~V}_{0}$ & $\mathrm{~V}_{7}$ & $\mathrm{~V}_{0}$ & $\mathrm{~V}_{7}$ \\
\cline { 2 - 8 } & -1 & $\mathrm{~V}_{1}$ & $\mathrm{~V}_{5}$ & $\mathrm{~V}_{4}$ & $\mathrm{~V}_{6}$ & $\mathrm{~V}_{2}$ & $\mathrm{~V}_{3}$ \\
\hline
\end{tabular}

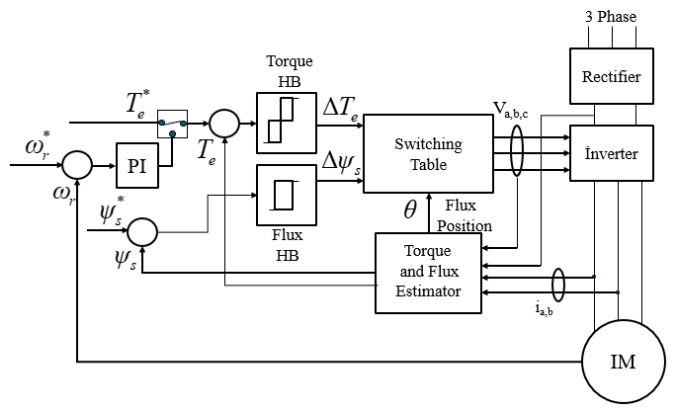

Fig. 2. Block scheme of the DTC based IM drives.

\section{INDUCTION MOTOR MODEL CONSIDERING CORE LOSSES}

In order to determine the required optimal stator flux for increasing the efficiency of the IM, the losses must be modelled. In IM modeling, the core loss is usually neglected $[21,22]$. However, the core loss must not be neglected for energy optimization and is taken into account in the dynamic model of induction motor through the core loss resistance $R_{F e}$ as shown in Figure 3. The core loss of IM includes eddy current loss component $P_{F e}^{e}$ and hysteresis loss component $P_{F e}^{h}$. These losses are given in (3) and (4):

$$
\begin{aligned}
& P_{F e}^{e}=k_{e} \omega_{s}^{2} \Phi^{2} \\
& P_{F e}^{h}=k_{h} \omega_{s} \Phi^{2}
\end{aligned}
$$


where $\omega_{s}$ is electrical angular speed, $\Phi$ is flux level, $k_{e}$ and $k_{h}$ are coefficients related to eddy current and hysteresis losses, respectively.

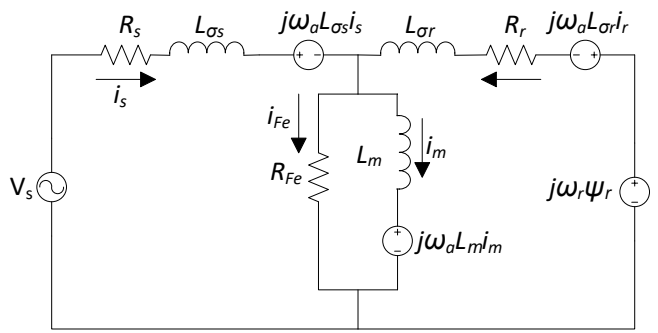

Fig. 3. Equivalent circuit of IM at a general rotating reference frame.

While the hysteresis loss is proportional to $\omega_{s}$, eddy current loss is proportional to $\omega_{s}^{2}$. Therefore, eddy current loss is dominant over hysteresis loss in a high frequency region. The stator core loss $P_{F e}^{S}$ and rotor core loss $P_{F e}^{r}$ in an IM can be calculated approximately by the following equations:

$$
\begin{aligned}
P_{F e}^{s} & =\left[k_{e} \omega_{s}^{2}+k_{h} \omega_{s}\right] \Phi_{m}^{2} \cong \frac{\omega_{s}^{2} \Phi_{m}^{2}}{1 / k_{e}}=\frac{\omega_{s}^{2} \Phi_{m}^{2}}{R_{F e}} \\
P_{F e}^{r} & =\left[k_{e} \omega_{s l}{ }^{2}+k_{h} \omega_{s l}\right] \Phi_{m}^{2} \cong \frac{\omega_{s l}{ }^{2} \Phi_{m}^{2}}{1 / k_{e}} \\
& =\frac{s^{2} \omega_{s}{ }^{2} \Phi_{m}^{2}}{1 / k_{e}}=\frac{\omega_{s}{ }^{2} \Phi_{m}^{2}}{R_{F e} / s^{2}}
\end{aligned}
$$

where $R_{F e}$ is the core loss resistance, $s$ is the slip, $\omega_{s l}$ is the slip angular speed, $\omega_{r}$ is the rotor angular speed, $\omega_{s l}=\omega_{s}-\omega_{r}=$ $s \omega_{s}$ and $\phi_{m}$ is the airgap flux. $\omega_{s} \phi_{m}$ represents the airgap voltage. Notice, that the rotor core loss is much smaller than the stator core loss, since $\left|s \omega_{s}\right| \leq\left|\omega_{s}\right|$.

According to Figure 4 we write the current and voltage equations related to the stator and rotor in the synchronous reference frame:

$$
\begin{aligned}
& V_{d s}=R_{s} i_{d s}+L_{\sigma s} \frac{d i_{d s}}{d t}+L_{m} \frac{d i_{d m}}{d t}-\omega_{s}\left(L_{\sigma s} i_{q s}+L_{m} i_{q m}\right) \\
& V_{q s}=R_{s} i_{q s}+L_{\sigma s} \frac{d i_{q s}}{d t}+L_{m} \frac{d i_{q m}}{d t}+\omega_{s}\left(L_{\sigma s} i_{d s}+L_{m} i_{d m}\right) \\
& 0=R_{r} i_{d r}+L_{\sigma r} \frac{d i_{d r}}{d t}+L_{m} \frac{d i_{d m}}{d t}-\omega_{s l}\left(L_{\sigma r} i_{q r}+L_{m} i_{q m}\right) \\
& 0=R_{r} i_{q r}+L_{\sigma r} \frac{d i_{q r}}{d t}+L_{m} \frac{d i_{q m}}{d t}+\omega_{s l}\left(L_{\sigma r} i_{d r}+L_{m} i_{d m}\right) \\
& i_{d s}+i_{d r}=i_{d m}+\frac{s^{2}+1}{R_{F e}}\left(L_{m} \frac{d i_{d m}}{d t}-\omega_{s} L_{m} i_{q m}\right) \\
& i_{q s}+i_{q r}=i_{q m}+\frac{s^{2}+1}{R_{F e}}\left(L_{m} \frac{d i_{q m}}{d t}+\omega_{s} L_{m} i_{d m}\right)
\end{aligned}
$$




$$
\begin{aligned}
& i_{d m} \cong i_{d s}+i_{d r} \\
& i_{q m} \cong i_{q s}+i_{q r}
\end{aligned}
$$

The magnetizing voltage components are approximated by:

$$
\begin{aligned}
& V_{d m}=L_{m} \frac{d\left(i_{d s}+i_{d r}\right)}{d t}-\omega_{s} L_{m}\left(i_{q s}+i_{q r}\right) \\
& V_{q m}=L_{m} \frac{d\left(i_{q s}+i_{q r}\right)}{d t}+\omega_{s} L_{m}\left(i_{d s}+i_{d r}\right)
\end{aligned}
$$

In (7)-(12) after substituting $i_{d m}$ and $i_{q m}$ by $i_{d s}+i_{d r}$ and $i_{q s}+i_{q r}$, respectively, a simplified model is obtained as follows:

$$
\begin{aligned}
& V_{d s}=R_{s} i_{d s}+L_{\sigma s} \frac{d i_{d s}}{d t}-\omega_{s} L_{\sigma s} i_{q s}+V_{d m} \\
& V_{q s}=R_{s} i_{q s}+L_{\sigma s} \frac{d i_{q s}}{d t}+\omega_{s} L_{\sigma s} i_{d s}+V_{q m} \\
& 0=R_{r} i_{d r}+L_{\sigma r} \frac{d i_{d r}}{d t}+\omega_{r}\left(L_{\sigma r} i_{q r}+L_{m} i_{q m}\right) \\
& \quad-\omega_{s} L_{\sigma r} i_{q r}+V_{d m} \\
& 0=R_{r} i_{q r}+L_{\sigma r} \frac{d i_{q r}}{d t}-\omega_{r}\left(L_{\sigma r} i_{d r}+L_{m} i_{d m}\right) \\
& +\omega_{s} L_{\sigma r} i_{d r}+V_{q m} \\
& i_{d s}+i_{d r}=i_{d m}+V_{d m} \frac{s^{2}+1}{R_{F e}} \\
& i_{q s}+i_{q r}=i_{q m}+V_{q m} \frac{s^{2}+1}{R_{F e}}
\end{aligned}
$$

\section{LOSS MINIMAZATION ALGORITHM}

The rotor flux-oriented reference frame is utilized for calculating losses and finding optimal stator flux, since it provides greater simplification. This frame is obtained by aligning the reference frame on the rotor flux axis. As a result, $\lambda_{q r}=\lambda_{q r}^{\prime}=0$. We define the rotor flux components as follows:

$$
\begin{aligned}
& \lambda_{d r}=L_{r} i_{d r}+L_{m} i_{d s} \\
& \lambda_{q r}=L_{r} i_{q r}+L_{m} i_{q s}=0
\end{aligned}
$$

where $L_{r}$ is the rotor inductance. The rotor current components are calculated from (25)-(26).

$$
\begin{aligned}
& i_{d r}=\frac{\lambda_{d r}-L_{m} i_{d s}}{L_{r}} \\
& i_{q r}=-\frac{L_{m} i_{q s}}{L_{r}}
\end{aligned}
$$

Replacing $i_{d r}$ and $i_{q r}$ in (17) and (18) we have:

$$
\begin{aligned}
& V_{d m}=\frac{L_{m} L_{\sigma r}}{L_{r}} \frac{d i_{d s}}{d t}+\frac{L_{m}}{L_{r}} \frac{d \lambda_{d r}}{d t}-\omega_{s} \frac{L_{m} L_{\sigma r}}{L_{r}} i_{q s} \\
& V_{q m}=\frac{L_{m} L_{\sigma r}}{L_{r}} \frac{d i_{q s}}{d t}+\omega_{s} \frac{L_{m}}{L_{r}}\left(L_{\sigma r} i_{d s}+\lambda_{d r}\right)
\end{aligned}
$$

In the steady state, $\frac{d i_{d s}}{d t}=\frac{d i_{q s}}{d t}=\frac{d \lambda_{d r}}{d t}=0$ and $i_{d r}=0$, since $\lambda_{d r}=L_{m} i_{d s}$. Therefore, in the steady state we have:

$$
\begin{aligned}
& V_{d m}=-\omega_{s} \frac{L_{m} L_{\sigma r}}{L_{r}} i_{q s} \\
& V_{q m}=\omega_{s} \frac{L_{m}}{L_{r}}\left(L_{\sigma r} i_{d s}+\lambda_{d r}\right)=\omega_{s} L_{m} i_{d s}
\end{aligned}
$$

Since slip is low $(s \ll 1)$ in normal operation of IM, the rotor core loss is neglected, hereafter. The core loss and copper loss are expressed by the following equations:

$$
\begin{aligned}
P_{F e} & =\frac{3}{2} \frac{\left(V_{d m}^{2}+V_{q m}^{2}\right)}{R_{F e}}=\frac{3}{2} \frac{\left(\omega_{s}^{2} L_{m}^{2}\left(\frac{L_{\sigma r}}{L_{r}}\right)^{2} i_{q s}^{2}+\omega_{s}^{2} L_{m}^{2} i_{d s}^{2}\right)}{R_{F e}} \\
P_{c u} & =\frac{3}{2}\left[R_{s}\left(i_{d s}^{2}+i_{q s}^{2}\right)+R_{r}\left(i_{d r}^{2}+i_{q r}^{2}\right)\right] \\
& =\frac{3}{2}\left[R_{s}\left(i_{d s}^{2}+i_{q s}^{2}\right)+R_{r}\left(\frac{L_{m}}{L_{r}}\right)^{2} i_{q s}^{2}\right]
\end{aligned}
$$

Also, the total loss is expressed as a function of electrical angular speed $\omega_{s}$, torque $T_{e}$ and $d$ axis component of rotor flux $\lambda_{d r}$ :

$$
\begin{aligned}
P_{\text {total }} & =\frac{3}{2} R_{s}\left(\frac{\lambda_{d r}}{L_{m}}\right)^{2}+\frac{2}{3}\left(\frac{T_{e}}{n_{p} L_{m} \lambda_{d r}}\right)^{2}\left(R_{s} L_{r}^{2}+R_{r} L_{m}^{2}\right) \\
& +\frac{3}{2}\left(\frac{n_{p} \omega_{s} \lambda_{d r}}{L_{r}}\right)^{2}\left(\frac{L_{\sigma r}^{2}+L_{m}^{2}}{R_{F e}}\right)+\frac{2}{3 R_{F e}}\left(\frac{T_{e} \omega_{s} L_{\sigma r}}{\lambda_{d r}}\right)^{2}
\end{aligned}
$$

where $n_{p}$ is the pole number.

\section{A. Proposed DTC based on Loss Minimization}

The torque of IM at steady state is given by:

$$
T_{e}=\frac{3}{2} n_{p} \frac{L_{m}}{L_{r}} \lambda_{d r} i_{q s}
$$

When the total loss term is examined, it is seen that it is closely related to the rotor flux level. In order to reduce core losses, the rotor flux, or in other words, $d$ axis stator current $i_{\mathrm{ds}}$, must be decreased. If the rotor flux is decreased, $q$ axis stator current $i_{\mathrm{qs}}$ must be increased very much in order to obtain the necessary torque causing a lot of copper loss. Therefore, optimal flux must be determined in order to provide balance between core loss and copper loss. Optimal rotor flux value is obtained by following equations:

$$
\frac{d P_{\text {total }}}{d \lambda_{d r}}=0
$$




$$
\lambda_{d r}^{o p t}=\sqrt{\frac{2}{3}} \sqrt{T_{e}^{r e f}}\left(\frac{A}{B}\right)^{1 / 4}
$$

where $\mathrm{A}$ and $\mathrm{B}$ are equal to

$$
\begin{aligned}
& A=\frac{R_{s} L_{r}^{2}+R_{r} L_{m}^{2}}{n_{p}^{2} L_{m}^{2}}+\frac{\omega_{s}^{2} L_{\sigma r}^{2}}{n_{p}^{2} R_{F e}} \\
& B=\frac{R_{s} R_{F e} L_{r}^{2}+\omega_{s} L_{m}^{2}\left(L_{m}^{2}+L_{\sigma r}^{2}\right)}{L_{m}^{2} R_{F e} L_{r}^{2}}
\end{aligned}
$$

However, in DTC control of IM, since stator flux control is required, optimal rotor flux is converted to optimal stator flux by the following equations:

$$
\begin{aligned}
& \psi_{s d}=\sigma L_{s} i_{s d}+\frac{L_{m}}{L_{r}} \psi_{r d}=\sigma \frac{L_{s}}{L_{m}} \psi_{r d}+\frac{L_{m}}{L_{r}} \psi_{r d} \\
& \psi_{s q}=\sigma L_{s} i_{s q}=\frac{2}{3} \frac{T_{e} L_{r}}{n_{p} L_{m} \psi_{r d}} \sigma L_{s} \\
& \psi_{s}=\sqrt{\psi_{s d}^{2}+\psi_{s q}^{2}} \\
& \psi_{s}^{o p t}=\psi_{s}^{r e f}=\frac{L_{s}}{L_{m}} \sqrt{\left(\psi_{d r}^{o p t}\right)^{2}+\left(\frac{2}{3} \frac{\sigma L_{r}}{n_{p}}\right)^{2}\left(\frac{T_{e}^{r e f}}{\psi_{d r}^{o p t}}\right)^{2}}
\end{aligned}
$$

where $\sigma=1-\frac{L_{m}^{2}}{L_{s} L_{r}}$, is the leakage factor and $L_{s}$ is the stator inductance.

The block scheme of the proposed DTC method for EVs is shown in Figure 5. The difference between the proposed DTC and conventional DTC methods is the usage of optimal stator flux block obtained by (44).

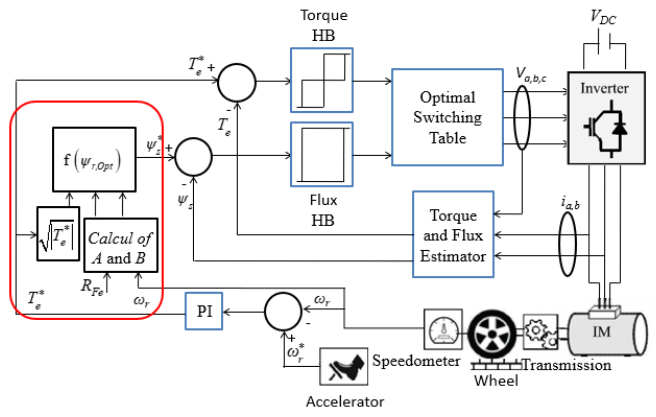

Fig. 5. Proposed DTC block scheme for EVs.

\section{Simulation RESUltS}

The proposed method is simulated by Matlab. An IM with capacity of $3 \mathrm{~kW}$ fed by a voltage source inverter is used in the simulation. The IM parameters are given in Table II. The applications aim to investigate the efficiency and dynamic performance of the proposed method, and compare it with the conventional DTC method. In this application, reference electrical angular speed is $250 \mathrm{rad} / \mathrm{s}$ and load torque is $2 \mathrm{Nm}$. In the conventional DTC, the reference stator flux is $1 \mathrm{~Wb}$ (rated conditions) while in the proposed DTC that is applied for $\mathrm{t}>2.5 \mathrm{~s}$, the reference stator flux is determined by the loss minimization algorithm. The results are shown in Figure 6.
TABLE II. INDUCTION MOTOR PARAMETERS

\begin{tabular}{|c|c|}
\hline Parameters & Values \\
\hline Power & $3 \mathrm{~kW}$ \\
\hline $\mathrm{R}_{\mathrm{s}}$ & $1.795 \Omega$ \\
\hline $\mathrm{R}_{\mathrm{r}}$ & $1.52 \Omega$ \\
\hline $\mathrm{R}_{\mathrm{Fe}}$ & $1340 \Omega$ \\
\hline $\mathrm{L}_{\mathrm{s}}=\mathrm{L}_{\mathrm{r}}$ & $0.2405 \mathrm{H}$ \\
\hline $\mathrm{L}_{\mathrm{m}}$ & $0.2323 \mathrm{H}$ \\
\hline $\mathrm{J}$ & $0.0044 \mathrm{kgm}^{2}$ \\
\hline $\mathrm{n}_{\mathrm{p}}$ & 1 \\
\hline
\end{tabular}

(a)
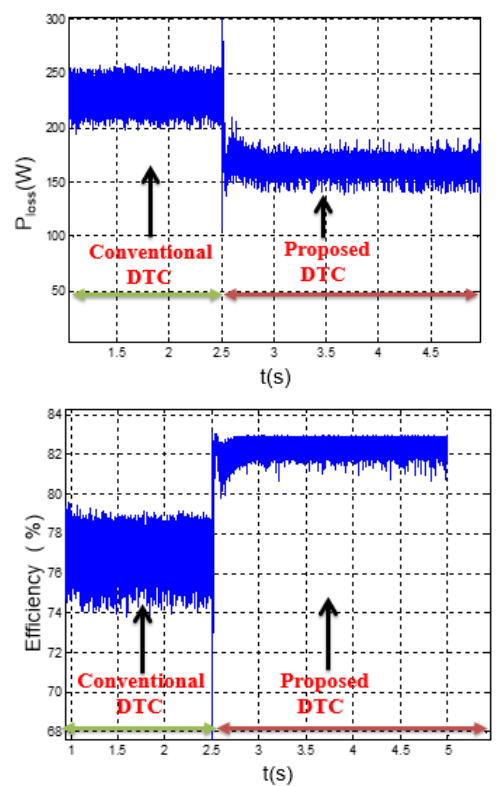

Fig. 6. (a) Total loss of IM, (b) Efficiency of IM.

(a)
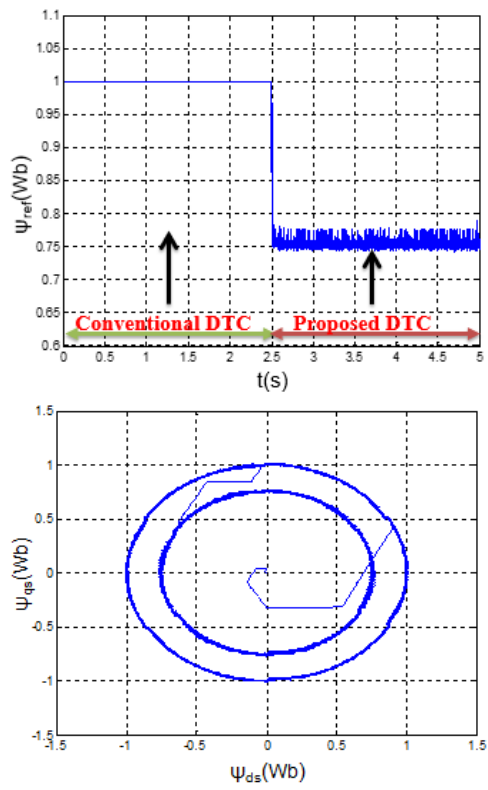

Fig. 7. (a) Reference stator flux, (b) Circular trajectory of stator flux.

As shown in Figure 6(a), the proposed method provides a significant losses reduction for $t>2.5 \mathrm{~s}$. Therefore, the efficiency is improved at the same rate as shown in Figure 6(b). The comparison of both DTC methods is given in Table III. Figure 
7(a) shows the variation of the reference stator flux. As shown in Figure 7(b), firstly the rated flux value is applied until IM reaches its steady state and then the stator flux reaches its optimal value apart from a small transient. Figure 8 shows the dynamic performance of the proposed DTC method. Speed control capability of the proposed approach is good in Figure 8 (a) and the torque ripple is comparatively decreased using the proposed DTC, Figure 8 (b).

(a)

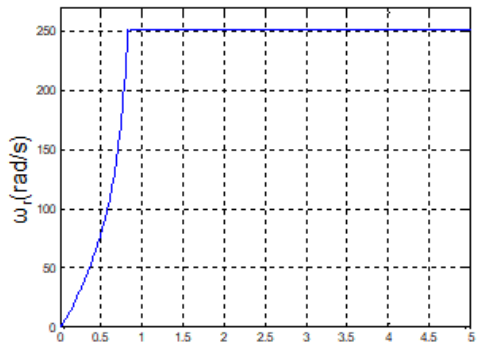

$\mathrm{t}(\mathrm{s})$

(b)

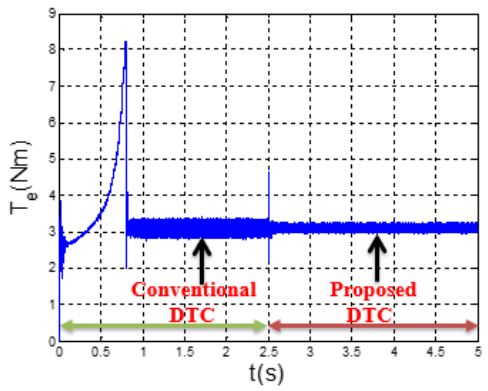

Fig. 8. (a) Speed of IM, (b) Torque of IM.

(a)
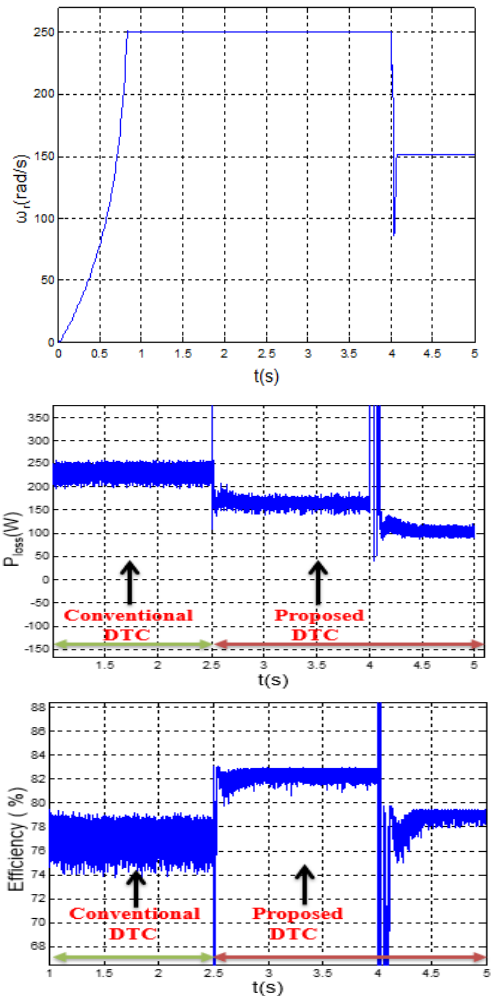

Fig. 9. The performance of the proposed method at variable speeds. (a) Speed of IM, (b) Total loss of IM, (c) Efficiency of IM.
TABLE III. COMPARISON OF CONVENTIONAL AND PROPOSED DTC

\begin{tabular}{|c|c|c|}
\hline Mean value & Conventional DTC & Proposed DTC \\
\hline Total loss (W) & 231.1961 & 166.2806 \\
\hline Efficiency (\%) & 77.1 & 82.4 \\
\hline Reference stator flux (Wb) & 1 & 0.7539 \\
\hline
\end{tabular}

Figure 9 shows the performance of the proposed method at variable speeds. Loss minimization algorithm starts for $t>2.5 \mathrm{~s}$. The reference electrical angular speed is reduced to $150 \mathrm{rad} / \mathrm{s}$ from $250 \mathrm{rad} / \mathrm{s}$ for $\mathrm{t}>4 \mathrm{~s}$. The total losses decrease due to the reduced output power as seen in Figure 9(b). The efficiency decreases due to the reduced rotor speed as seen in Figure 9(c). Figure 10 shows the performance of the proposed method at the variable loads. The loss minimization algorithm starts for $\mathrm{t}>2.5 \mathrm{~s}$. The load torque is decreased to $1 \mathrm{Nm}$ from $2 \mathrm{Nm}$ for $\mathrm{t}>4 \mathrm{~s}$. The total losses decrease due to the reduced output power as shown in Figure 10 (b). Although the motor operates at the lower load, the efficiency is almost the same as shown in Figure 10 (c).

(a)

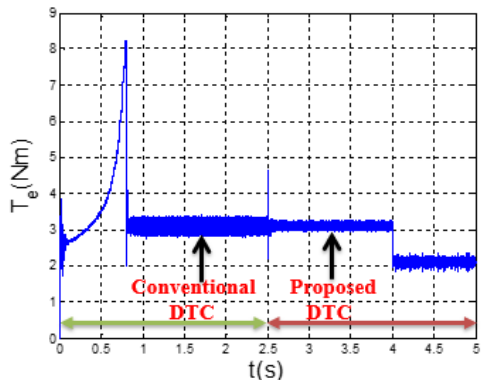

(b)
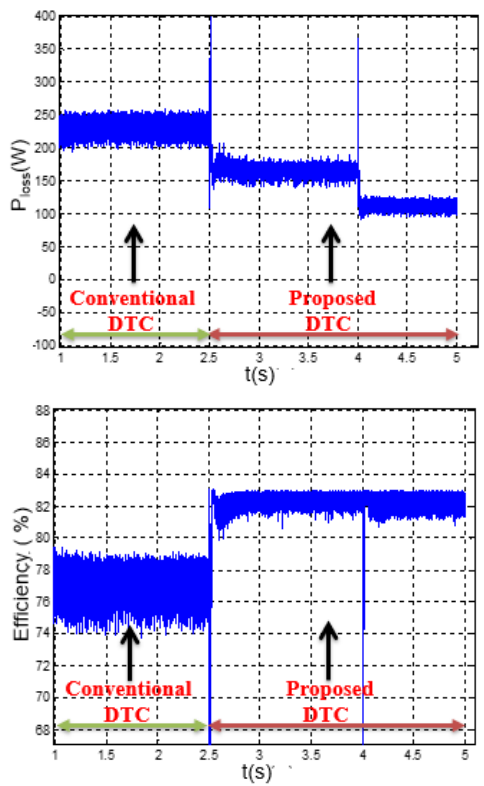

Fig. 10. The performance of the proposed method at variable loads. (a) Torque of IM, (b) Total loss of IM, (c) Efficiency of IM

\section{CONCLUSIONS}

In this paper, energy efficiency improvement of DTC based on IM drives is proposed for EV applications. Results show that the DTC method can be successfully combined with the proposed loss minimization algorithm, while maintaining a good dynamic response. Also, the proposed method decreases 
the torque ripple of DTC based IM. To eliminate disadvantages of neglecting core loss and the effect of leakage inductance, both are included in the motor model and a simplification is made by ignoring the current in the core loss resistance branch of the equivalent circuit of IM in the synchronous frame. Therefore, the proposed DTC method can be used effectively in EV applications to improve the efficiency and decrease the torque ripple by optimizing the stator flux.

\section{REFERENCES}

[1] D. Ziane, S. Aissou, A. Azib, T. Rekioua, "Performance test of the control strategy applied to the electric vehicle, in the case of FWD and 4WD", International Journal of Hdyrogen Energy, Vol. 39, No. 36, pp. 21259-21264, 2014

[2] Z. Mokrani, D. Rekioua, T. Rekioua, "Modeling, control and power management of hybrid photovoltaic fuel cells with battery bank supplying electric vehicle", International Journal of Hdyrogen Energy, Vol. 39, No. 27, pp. 15178-15187, 2014

[3] F. Tazerart, Z. Mokrani, D. Rekioua, T. Rekioua, "Direct torque control implementation with losses minimization of induction motor for electric vehicle applications with high operating life of the battery", International Journal of Hdyrogen Energy, Vol. 40, No. 39, pp. 13827-13838, 2015

[4] J. O. Estima, A. J. M. Cardoso, "Efficiency analysis of drive train topologies applied to electric/hybrid vehicles", IEEE Transactions on Vehicular Technology, Vol. 61, No. 3, pp. 1021-1031, 2012

[5] F. Sun, R. Xiong, H. He, "A systematic state-of-charge estimation framework for multi-cell battery pack in electric vehicles using bias correction technique", Applied Energy, Vol. 162, pp. 1399-1409, 2016

[6] M. Zeraouila, M. E. H. Benbouzid, D. Diallo, "Electric motor drive selection issues for HEV propulsion systems: a comparative study", IEEE Transactions on Vehicular Technology, Vol. 55, No. 6, pp. 17561764, 2006

[7] N. Kumar, T. R. Chelliah, S. P. Srivastava, "Adaptive control schemes for improving dynamic performance of efficiency-optimized induction motor drives", ISA Transactions, Vol. 57, pp. 301-310, 2015

[8] V. Ambrozic, G. Buja, R. Menis, "Band-constrained technique for direct torque control of induction motor", IEEE Transactions on Industrial Electronics, Vol. 51, No. 4, pp. 776-784, 2004

[9] S. Kaboli, E. V. Khajeh, M. R. Zolghadri, "Probabilistic voltage harmonic analysis of direct torque controlled induction motor drives", IEEE Transactions on Power Electronics, Vol. 21, No. 4, pp. 1041-1052, 2006

[10] T. Sutikno, N. R. N. Idris, A. Jidin, "A review of direct torque control of induction motors for sustainable reliability and energy efficient drives", Renewable and Sustainable Energy Reviews, Vol. 32, pp. 548-558, 2014

[11] M. C. D. Piazza, M. Pucci, "Techniques for efficiency improvement in PWM motor drives", Electric Power Systems Research, Vol. 136, pp. 270-280, 2016

[12] O. S. Ebrahim, M. A. Badr, A. S. Elgendy, P. K. Jain, "ANN-based optimal energy control of induction motor drive in pumping applications", IEEE Transactions on Energy Conversion, Vol. 25, No. 3, pp. 652-660, 2010

[13] A. M. Bazzi, P. T. Krein, "Review of methods for real-time loss minimization techniques in induction machines", IEEE Transactions on Industry Applications, Vol. 46, No. 6, pp. 2319-2328, 2010

[14] S. Sridharan, P. T. Krein, "Minimization of system-level losses in VSIbased induction motor drives: offline strategies", IEEE Transactions on Industry Applications, Vol. 53, No. 2, pp. 1096-1105, 2017

[15] M. Hajian, G. R. Arab Markadeh, J. Soltani, S. Hoseinnia, "Energy optimized sliding-mode control of sensorless induction motor drives", Energy Conversion and Management, Vol. 50, No. 9, pp. 2296-2306, 2009

[16] F. Farhani, C. B. Regaya, A. Zaafouri, A. Chaari, "Real time PIbackstepping induction machine drive with efficiency optimization", ISA Transactions, Vol. 70, pp. 348-356, 2017
[17] F. Farhani, A. Zaafouri, A. Chaari, "Real time induction motor efficiency optimization", Journal of the Franklin Institute, Vol. 354, No. 8, pp. 3289-3304, 2017

[18] A. Haddoun, M. E. H. Benbouzid, D. Diallo, R. Abdessemed, J. Ghouili, K. Srairi, "A loss-minimization DTC scheme for EV induction motors", IEEE Transactions on Vehicular Technology, Vol. 56, No. 1, pp. 81-88, 2007

[19] M. N. Uddin, S. W. Nam, "New online loss-minimization-based control of an induction motor drive", IEEE Transactions on Power Electronics, Vol. 23, No. 2, pp. 926-933, 2008

[20] M. N. Uddin, S. W. Nam, "Development of a nonlinear and model-based online loss minimization control of an IM drive", IEEE Transactions on Energy Conversion, Vol. 23, No. 4, pp. 1015-1024, 2008

[21] A. Borisevich, G. Schullerus, "Energy efficient control of an induction machine under torque step changes", IEEE Transactions on Energy Conversion, Vol. 31, No. 4, pp. 1295-1303, 2016

[22] A. Ammar, A. Benakcha, A. Bourek, "Closed loop torque SVM-DTC based on robust super twisting speed controller for induction motor drive with efficiency optimization", International Journal of Hdyrogen Energy, Vol. 42, No. 28, pp. 17940-17952, 2017

[23] M. Aktas, H. I. Okumus, "Stator resistance estimation using ANN in DTC IM drives", Turkish Journal of Electrical Engineering and Computer Sciences, Vol. 18, No. 2, pp. 197-210, 2010

[24] H. I. Okumus, M. Aktas, "Direct torque control of induction machine drives using adaptive hysteresis band for constant switching frequency", IEEE International Electric Machines and Drives Conference, Antalya, Turkey, May 3-5, 2007

[25] F. Abrahamsen, F. Blaabjerg, J. K. Pedersen, P. B. Thoegersen, "Efficiency-optimized control of medium-size induction motor drives", IEEE Transactions on Industry Applications, Vol. 37, No. 6, pp. 17611767,2001

[26] S. Lim, K. Nam, "Loss-minimising control scheme for induction motors", IEE Proceedings-Electric Power Applications, Vol. 151, No. 4, pp. 385-397, 2004 